Revista Brasileira de

Engenharia Agrícola e Ambiental

v. 15, n. 8, p. $853-860,2011$

Campina Grande, PB, UAEA/UFCG - http://www.agriambi.com.br

agriambi Protocolo 108.09 - 14/07/2009 • Aprovado em 01/06/2011

\title{
Tolerância ao déficit hídrico em genótipos de feijão-caupi
}

\author{
Sebastião P. do N ascimento ${ }^{1}$, Edson A. Bastos ${ }^{2}$, Eugênio C. E. Araújo ${ }^{2}$, \\ Francisco R. Freire Filho ${ }^{2} \&$ Everaldo M. da Silva ${ }^{3}$
}

\begin{abstract}
RESU MO
O bjetivou-se, neste trabalho, avaliar o efeito do déficit hídrico sobre as características fisiológicas e produtivas do feijão-caupi e selecionar genótipos tolerantes à seca. A valiaram-se a condutância estomática, o potencial hídrico foliar, a temperatura das folhas e a produtividade de grãos de 20 genótipos de feijãocaupi nas condições de solo e clima de Teresina, Piauí, no ano de 2008 e se conduziram dois experimentos em delineamento de blocos ao acaso com 20 tratamentos e quatro repetições, um sob déficit hídrico durante a fase reprodutiva e outro sob irrigação plena, para fins de comparação. 0 déficit hídrico, que foi obtido aplicando-se aproximadamente metade da lâmina requerida pelo feijão-caupi, reduziu em $72 \%$ a condutância estomática, $62 \%$ o potencial de água nas folhas, $60 \%$ a produção de grãos e aumentou em $11,7 \%$ a temperatura foliar. $\mathrm{N}$ as condições de déficit hídrico treze genótipos produziram acima da média (466 $\mathrm{kg} \mathrm{ha}^{-1}$ ), com destaque para o BRS-Paraguaçu, Pingo-de-ouro-1-2 e Pingo-de-ouro-2, que produziram $712 \mathrm{~kg} \mathrm{ha}^{-1}, 667 \mathrm{~kg} \mathrm{ha}^{-1}$ e $642 \mathrm{~kg} \mathrm{ha}^{-1}$, respectivamente. Em média, a produtividade de grãos dos genótipos sob irrigação plena foi $150 \%$ superior.
\end{abstract}

Palavras-chave: Vigna unguiculata(L.) Walp., potencial de água na folha, condutância estomática, temperatura foliar

\section{Tolerance to water deficit of cowpea genotypes}

\begin{abstract}
The objective of this study was to evaluate physiological and productive characteristics of cowpea under water deficit and total irrigation, under soil and climate conditions of Teresina, Piauí State, in 2008. The stomatal conductance, leaf water potential, leaf temperature and grain yield of twenty cowpea cultivars were evaluated. Two experiments were carried out in a randomized block design with 20 treatments and four replications, one under water deficit during the reproductive phase and another one under total irrigation. The water deficit was obtained applying half of the water depth required by cowpea. The water deficit reduced $72 \%$ of the stomatal conductance, $40 \%$ the leaf transpiration, $62 \%$ of the leaf water potential, $60 \%$ of the grain yield and increased $11.7 \%$ the leaf temperature. Under water deficit, 13 genotypes produced above average (466 kg ha-1), and BRS-Paraguaçu, Pingo-de-ouro-1-2 and Pingo-de-ouro-2 presented the best grain yield with712 $\mathrm{kg} \mathrm{ha}^{-1}, 667 \mathrm{~kg} \mathrm{ha}^{-1}$ and $642 \mathrm{~kg} \mathrm{ha}^{-1}$, respectively. The average grain yield of the experiment under total irrigation was $150 \%$ higher.
\end{abstract}

Key words: Vigna unguiculata(L.) Walp., leaf water potential, stomatal conductance, leaf temperature

\footnotetext{
${ }^{1}$ Instituto Federal de Educação Ciência e Tecnologia do Piauí, Rua 06, S/N - Bairro Nova Corrente, CEP 64980-000, Corrente, PI.Fone (89) $3573-2620$. E-mail: spnascimento@ifpi.edu.br

2 Embrapa Meio-Norte, Av. Duque de Caxias, 5650, Buenos Aires,CEP 64006-220, Teresina, PI. Fone: (86) 3089-9100 E-mail: edson@cpamn.embrapa.br; emerito@cpamn.embrapa.br, freire@cpamn.embrapa.br

ESALQ/U SP, Av. Pádua Dias, 11,Piracicaba, SP.Fone: (19) 3447-8561 Ramal: 8561. E-mail: everaldo@usp.br
} 


\section{INTRODUÇÃO}

O feijão-caupi (Vigna unguiculata (L.) Walp.) é cultivado predominantemente nas regiões Norte e Nordeste do Brasil. Apesar de adaptadas às condições ambientais de cultivo, apresentam produtividade média de apenas $355 \mathrm{~kg} \mathrm{ha}^{-1}$ (CONAB, 2008). Esta baixa produtividade é resultante de vários fatores, como o uso de sementes não melhoradas, o cultivo em solos de baixa fertilidade e a ocorrência de precipitações pluviométricas irregulares. A deficiência hídrica é condição comum no Nordeste do País, sendo um dos fatores que comumente reduzem a produtividade do feijão-caupi (Mendes et al., 2007). A planta é classificada como moderadamente tolerante, tanto à deficiência hídrica quanto ao excesso de água no solo (Boyer, 1978). O requerimento de água desta cultura é variável com o seu estádio de desenvolvimento (Lima et al., 2006) e aumenta de um valor mínimo na germinação até um valor máximo na floração e formação de vagens, decrescendo a partir do início da maturação (Bastos et al., 2008).

Diante da importância do feijão-caupi para o norte-nordeste do Brasil, torna-se imprescindível a realização de estudos visando avaliar o desempenho de cultivares desenvolvidas para o cultivo em regime de sequeiro, frente às limitações hídricas impostas que ocorrem em diferentes fases de crescimento. Sousa et al. (2009) verificaram que o efeito do estresse hídrico em feijoeiro causa reduções nos componentes de produção e é mais severo quando ocorre nas fases de floração e frutificação. Guimarães et al. (2006) também constataram que a deficiência hídrica nas plantas é tanto maior quanto menor o suprimento de água pelas raízes.

As respostas das plantas às condições de estresse hídrico variam de acordo com a espécie, cultivar, tempo de exposição e fatores edáficos, entre outros. Não existe uma única variável fisiológica que, por si só, seja indicativa de tolerância à seca. Segundo Nogueira et al. (2001), o ideal é avaliar-se mais de uma variável, tais como potencial hídrico, condutância estomática, temperatura e transpiração foliar, considerados importantes para avaliar as respostas das espécies vegetais ao estresse hídrico.

O estresse hídrico tem efeito em diversos processos fisiológicos das plantas e já foi objeto de pesquisas realizadas por Gomes Filho \& Tahin (2002), Oliveira et al. (2005), Mendes et al. (2007) e Endres et al. (2010). A avaliação do status hídrico das plantas quando submetidas à deficiência hídrica nas fases vegetativa e reprodutiva, demonstra que cultivares de feijãode-corda sofreram reduções significativas no potencial hídrico foliar, condutância estomática e transpiração foliar, com consequente aumento na temperatura da folha (Mendes et al., 2007). Em plantas de feijão o déficit hídrico diminui a condutância estomática e aumenta a resistência difusiva ao vapor de água, mediante fechamento dos estômatos, reduzindo a transpiração e, em consequência, o suprimento de $\mathrm{CO}_{2}$ para a fotossíntese (Oliveira et al., 2005).Para Larcher (2000), os estômatos atuam como moduladores da perda de água pela transpiração respondendo ao déficit hídrico com a alteração da abertura do poro a uma faixa crítica de valores do potencial hídrico foliar.

Quanto menor a quantidade de água no solo mais negativo deve ser o potencial de água na folha desenvolvido pelos vegetais, formando um gradiente que favoreça a absorção de água pelas plantas (Larcher, 2000). Os valores médios de potencial hídrico indicados para os diferentes grupos de planta dependem do tipo de solo e do tipo de vegetação, podendo ser ainda menores devido à adaptação das plantas em relação à deficiência hídrica (Larcher, 2000). Segundo Boyer (1978), os valores aproximados de potenciais de água letais para algumas espécies vegetais, variam de -1,4 a -6,0 MPa, para o tomateiro e a acácia, respectivamente; já para o feijão-comum e para o feijão-caupi esses valores de potencial hídrico foliar são de $-1,5$ a -2,5 MPa, respectivamente, o que os classifica como plantas sensíveis e moderadamente tolerantes ao déficit de água no solo.

A temperatura foliar, a relação entre temperatura foliar e a temperatura do ar ou mesmo a diferença entre ambas, têm sido empregadas por diversos pesquisadores como indicadoras das condições hídricas das plantas (Oliveira et al., 2005). Em sua pesquisa, Guimarães et al. (2006) constataram que a temperatura do dossel se correlacionou significativamente com o potencial da água nas folhas e sua medição, por ser rápida e nãodestrutiva, mostrou tratar-se de uma técnica útil no processo de seleção de genótipos de feijoeiro para regiões sujeitas a deficiência hídrica. Dados da literatura mostram que, sob condições de déficit hídrico, a temperatura foliar se apresenta, comumente, mais elevada do que a temperatura do ar, resultando em aumento na relação temperatura foliar/ambiente (Mendes et al., 2007).

O desenvolvimento de cultivares mais tolerantes a períodos de deficiência hídrica no solo, tal como o desenvolvimento de mecanismos que auxiliem as plantas a tolerar períodos prolongados de seca, será essencial na manutenção da produção agrícola brasileira e mundial (Nepomuceno et al., 2001). As diferentes reações de cada genótipo a essas variações permitem que ele possa tolerá-las quando em níveis críticos mantendo, ainda assim, taxas adequadas de fotossíntese (Ribeiro et al., 2004). Cultivares de feijão-caupi apresentam diferentes respostas fisiológicas quando submetidos a déficit de água no solo (Bezerra et al., 2003).

Objetivou-se, neste trabalho, analisar o efeito do déficit hídrico aplicado no estádio reprodutivo sobre as características fisiológicas e produtivas do feijão-caupi, com vistas a selecionar genótipos com tolerância à deficiência hídrica.

\section{Material e mÉTodos}

Os estudos da avaliação de genótipos de feijão-caupi quanto a tolerância à seca, coordenados pela Embrapa Meio-Norte, se iniciaram em 2005, com a avaliação de 80 genótipos do Banco Ativo de Germoplasma da Embrapa Meio-Norte, as quais foram avaliadas no final do período chuvoso, sem a utilização de irrigação. Neste mesmo ano se acresceram 35 novos genótipos, que foram avaliados durante o período seco e sob irrigação tipo aspersão convencional controlada, quando se selecionaram 34, os quais foram avaliados em 2006 sob estresse hídrico durante o período reprodutivo. A seleção se baseou no estande final, no início da floração, no valor de cultivo, na ocorrência de viroses, no peso de 100 grãos e na produção por 
parcela. Em ambas as etapas os tratamentos foram delineados em blocos de Federer ou delineamento aumentado, com quatro conjuntos. Nos dois experimentos as parcelas foram representadas por uma fileira de $3,0 \mathrm{~m}$, o espaçamento entre fileiras foi de $1,40 \mathrm{~m}$ e entre covas dentro da fileira de $0,15 \mathrm{~m}$ tendo-se, deste modo, 20 plantas por parcela.

A partir desses 34 genótipos foram selecionados 20, os quais foram avaliados nos anos agrícolas de 2007 e 2008, sob aspersão convencional e sob déficit hídrico durante a fase reprodutiva, conduzidos no período de setembro a novembro incluindo-se, nas avaliações, variáveis fisiológicas como potencial hídrico foliar, condutância estomática, transpiração e temperatura foliar. No mesmo ano o estresse foi severo atingindo mais de $90 \%$ da água disponível no solo dificultando a seleção uma vez que o desempenho produtivo foi muito baixo para todos os genótipos avaliados. Desta forma se procedeu novamente em 2008, à avaliação dos 20 genótipos, proporcionando um estresse menos severo.

Avaliaram-se, em 2008, os seguintes genótipos de feijãocaupi: Pitiúba, Tvu 36, TE-898, Capela, Canapuzinho, Canapu, BA, Canapuzinho, PE, CNCx 689-128G, BR17-Gurguéia, BRSParaguaçu, Patativa, TE96-290-12G (BRS Xiquexique), Pingo-de-ouro-1, Pingo-de-ouro-2, Pingo-de-ouro-1-2, Canapuzinho-2, EPACE-10, IPA-206, Tracuateua-192 e Santo Inácio.

Os experimentos foram instalados no campo experimental da Empresa Brasileira de Pesquisa Agropecuária, Embrapa MeioNorte, localizada em Teresina, PI ( $05^{\circ} 05^{\prime}$ de latitude sul; $42^{\circ} 48^{\prime}$ de longitude oeste e 74,4 $\mathrm{m}$ de altitude), no período de agosto a outubro de 2008. O clima do município é do tipo Aw (clima tropical de estações úmida e seca), segundo a classificação de Köppen. As médias anuais de umidade relativa do ar e precipitação pluviométrica são de $72,6 \%$ e $1.336 \mathrm{~mm}$ respectivamente, concentrando-se a maioria das chuvas nos meses de janeiro a abril (Bastos et al., 2008). Os valores médios mensais de temperatura máxima, média e mínima do ar para os meses de agosto a outubro, foram 36,6, 29 e $21,9{ }^{\circ} \mathrm{C}$, respectivamente, durante os experimentos. A umidade relativa média e o total de precipitação durante os meses de agosto a outubro foram de $53 \%$ e $9 \mathrm{~mm}$, respectivamente.

O solo da área experimental é um Argissolo Amarelo de textura franco-arenosa, cujas características físicas e químicas são apresentadas, respectivamente, nas Tabelas 1 e 2 .

A análise de solo mostrou a necessidade de correção da acidez e a calagem foi feita com base no método da saturação por bases.

O delineamento experimental empregado foi o de blocos ao acaso, com quatro repetições. Semearam-se, manualmente, quatro sementes por cova no espaçamento de $0,8 \times 0,25 \mathrm{~m}$, no
Tabela 1. Características físicas do solo da área experimental da Embrapa M eio-N orte. Teresina, PI, 2008

\begin{tabular}{lrrrr}
\hline \multirow{2}{*}{ Característica } & \multicolumn{5}{c}{ Camadas do solo (cm) } \\
\cline { 2 - 5 } & $\mathbf{0 - 1 5}$ & $\mathbf{1 5 - 4 5}$ & $\mathbf{4 5 - 7 0}$ & \multicolumn{1}{c}{$\mathbf{7 0}$} \\
Densidade do solo $\left(\mathrm{kg} \mathrm{dm}^{-3}\right)$ & 1,39 & 1,33 & 1,32 & 1,27 \\
Areia $\left(\mathrm{g} \mathrm{kg}^{-1}\right)$ & 799,00 & 627,00 & 627,50 & 550,00 \\
Silte $\left(\mathrm{g} \mathrm{kg}^{-1}\right)$ & 85,00 & 127,00 & 96,50 & 144,00 \\
Argila $\left(\mathrm{g} \mathrm{kg}^{-1}\right)$ & 116,00 & 246,00 & 276,00 & 306,00 \\
\hline Fonte: Laboratório de Solos da Embrapa Meio-Norte & & &
\end{tabular}

dia 06 de agosto de 2008, realizando-se o desbaste aos 15 dias após semeadura (DAS), deixando-se duas plantas por cova para um stand final de 100.000 plantas por hectare. A parcela consistiu de uma área de 3,20 x 5,0 m, totalizando $16 \mathrm{~m}^{2}$, composta de quatro fileiras de plantas; como área útil consideraram-se as duas fileiras centrais. A adubação de fundação consistiu na aplicação de $20 \mathrm{~kg} \mathrm{ha}^{-1} \mathrm{de} \mathrm{N}, 40 \mathrm{~kg} \mathrm{ha}^{-1}$ de $\mathrm{P}_{2} \mathrm{O}_{5}$ e $30 \mathrm{~kg} \mathrm{ha}^{-1}$ de $\mathrm{K}_{2} \mathrm{O}$. Realizaram-se, durante a condução do experimento, tratos culturais, de modo a manter a área livre de plantas invasoras, doenças e pragas; aos 22 e 30 DAS aplicou-se macro e micronutrientes (Niphokana 1\%) via foliar, visando ao bom desenvolvimento da parte aérea.

A irrigação foi feita por um sistema de aspersão convencional fixo, com aspersores espaçados $12 \times 12 \mathrm{~m}$, com bocais de 3,4 x 2,6 mm de diâmetro e vazão de 1,07 $\mathrm{m}^{3} \mathrm{~h}^{-1}$ a uma pressão de serviço de 20 mca. Para o cálculo da lâmina de irrigação tomou-se como base a evapotranspiração de referência estimada por Penman-Monteith e nos coeficientes de cultura (Kc) obtidos por Bastos et al. (2008).

Obtiveram-se os dados climatológicos de uma estação agrometeorológica automática distante aproximadamente 500 $\mathrm{m}$ da área experimental. $\mathrm{O}$ teor de água no solo foi monitorado diariamente por meio da sonda de capacitância Diviner $2000^{\circledR}$, em camadas de 0,10 até $0,70 \mathrm{~m}$ de profundidade.

Os valores de conteúdo da umidade do solo referentes à capacidade de campo $(-10 \mathrm{kPa})$ e ponto de murcha permanente $(-1.500 \mathrm{kPa})$, considerando-se a camada de 0 a $0,45 \mathrm{~m}$, foram de 21e $9,0 \%$ à base de volume, respectivamente.

Avaliaram-se o potencial hídrico foliar $\left(\emptyset_{\mathrm{f}}\right)$, a condutância estomática $\left(\mathrm{g}_{\mathrm{s}}\right)$ e a temperatura das folhas (Tf), cujas leituras foram efetuadas entre 6:30 e 9:30 h da manhã, aos 43 dias após a semeadura (fase reprodutiva), ocasião em que as plantas apresentaram sinais agudos de deficiência hídrica. As determinações da $g_{s}$ e $\mathrm{Tf}$ foram efetuadas nas faces abaxial e adaxial do folíolo central da terceira folha a partir do ápice totalmente expandido (Nogueira et al., 2001) e sem sinais de senescência ou herbivoria, tomando-se duas plantas por parcela e se utilizando um porômetro de equilíbrio dinâmico, modelo "LICOR 1600 steady state" da LICOR Inc., Lincoln, Nebraska,

Tabela 2. Características químicas do solo da área experimental da Embrapa Meio-N orte. Teresina, PI, 2008

\begin{tabular}{|c|c|c|c|c|c|c|c|c|c|c|}
\hline \multirow{2}{*}{\multicolumn{2}{|c|}{$\begin{array}{c}\text { Horizonte } \\
\text { e profundidade }\end{array}$}} & \multirow{2}{*}{$\begin{array}{c}\mathrm{pH} \\
\text { (água) }\end{array}$} & \multirow{2}{*}{$\begin{array}{c}P \\
\mathrm{mg} \mathrm{dm}\end{array}$} & $\mathrm{K}^{+}$ & $\mathrm{Ca}^{2+}$ & $\mathrm{Mg}^{2+}$ & $\mathrm{Na}^{+}$ & $\mathrm{H}^{+}+\mathrm{Al}^{3+}$ & CTC & \multirow{2}{*}{$\begin{array}{l}\mathbf{V} \\
\%\end{array}$} \\
\hline & & & & \multicolumn{6}{|c|}{$\mathrm{cmol}_{\mathrm{c}} \mathrm{dm}^{-3}$} & \\
\hline AP & $0-15 \mathrm{~cm}$ & 5,86 & 26,40 & 0,15 & 2,08 & 0,86 & 0,27 & 2,01 & 5,37 & 62,53 \\
\hline$A B$ & $15-45 \mathrm{~cm}$ & 4,61 & 2,20 & 0,04 & 1,76 & 0,71 & 0,10 & 4,57 & 7,18 & 36,35 \\
\hline $\mathrm{Bt}$ & $45-70 \mathrm{~cm}$ & 4,30 & 1,70 & 0,02 & 0,45 & 0,68 & 0,07 & 3,91 & 5,13 & 23,78 \\
\hline$C$ & $>70 \mathrm{~cm}$ & 4,28 & 1,10 & 0,02 & 0,83 & 0,72 & 0,08 & 2,59 & 4,24 & 38,91 \\
\hline
\end{tabular}


USA. Procedeu-se aos cuidados de rotina preconizados para manuseio do equipamento, como a calibragem, antes do início das leituras.

O potencial da água da folha $\left(\varnothing_{f}\right)$ foi determinado através de uma câmara de pressão de Scholander (Scholander et al., 1965), modelo 3035 da "Soil Moisture Equipment Corp", Santa Bárbara, Califórnia (EUA). Para essas avaliações se utilizaram as folhas nas quais foram realizadas as medidas porométricas.

Avaliou-se, por ocasião da colheita, a produtividade de grãos em $\mathrm{kg} \mathrm{ha}^{-1}$ corrigida para $13 \%$ de umidade. Os resultados foram submetidos à análise de variância tendo-se realizado a comparação entre médias, pelo teste de Scott-Knott, a 5\% de probabilidade, por meio do software SAEG (2007).

\section{RESULTADOS E DISCUSSÃO}

O monitoramento da umidade do solo indicou que no experimento sem déficit hídrico os valores mínimos de tensão alcançaram $-52 \mathrm{kPa}$, equivalendo a $45 \%$ de esgotamento de água no solo. Por outro lado, sob déficit hídrico a tensão crítica alcançou $-282 \mathrm{kPa}$, correspondendo a uma fração de $75 \%$ de esgotamento de água disponível no solo, demonstrando que houve um estresse hídrico moderado, conforme observado por Bezerra et al. (2003). Nascimento et al. (2004) constataram que o nível crescente de déficit hídrico afetou drasticamente o desempenho do genótipo de feijão-caupi IPA 206; verificaram, também, reduções significativas nos componentes de produção para os níveis de 60 e $40 \%$ de água disponível no solo.

Os resultados da comparação das médias e a análise de variância das variáveis fisiológicas e produtiva se encontram na Tabela 3. Houve diferenças significativas entre genótipos para todas as variáveis estudadas. Ao se reduzir a lâmina de irrigação de 300 para $190 \mathrm{~mm}$, deu-se redução de $62 \%$ no potencial hídrico foliar $\left(\varnothing_{\mathrm{f}}\right), 72 \%$ na condutância estomática $\left(\mathrm{g}_{\mathrm{s}}\right), 60 \%$ na produtividade de grãos e um aumento de $11,7 \%$ na temperatura foliar ( $\mathrm{Tf}$ ), confirmando resultados com cultivares de feijão obtidos por Gomes Filho \& Tahin (2002), Oliveira et al. (2005), Guimarães et al. (2006), Mendes et al. (2007) e Sousa et al. (2009).

Sob irrigação plena verificou-se um $\emptyset_{\mathrm{f}}$ máximo e mínimo de -1,14, -0,85 MPa (Tabela 3), para os genótipos Santo Inácio e BRS-Paraguaçu, respectivamente, resultando em uma variação de $25 \%$ entre os genótipos com maior e menor $\emptyset_{\mathrm{f}}$, enquanto na condição de estresse hídrico referidos valores decresceram para $\varnothing_{\mathrm{f}}$ máximo e mínimo de -2,05 e-1,22 MPa, para os genótipos Tracuateua-192 e BRS Paraguaçu, respectivamente, resultando em uma variação de $40 \%$. Resultados semelhantes obtiveram Mendes et al. (2007), ao verificarem valores máximo e mínimo de -1,90 e-1,05MPa, respectivamente, correspondendo a uma variação de $43 \%$ no $\emptyset_{\mathrm{f}}$ para cultivares de feijão-caupi com o déficit hídrico aplicado na fase reprodutiva. No entanto, estão em desacordo com os resultados de Guimarães et al. (2006), que verificaram $\varnothing_{\mathrm{f}}$ máximos e mínimos de -0,3 e -1,07 MPa, respectivamente, com déficit hídrico imposto na fase reprodutiva e divergem totalmente dos obtidos em feijão-comum por Souza et al. (2004) e Micheletto et al. (2007), que encontraram valores de $\varnothing_{f}$ de $-2,30$ e $-2,57 \mathrm{MPa}$, respectivamente. Ressalta-se, entretanto, que os valores de $\emptyset_{\mathrm{f}}$ foliar podem variar em razão do estádio fenológico da cultura, da cultivar, da disponibilidade hídrica do solo, do déficit de pressão de vapor do ar e do horário e local em que são registrados (Nogueira et al., 1998).

Tabela 3. M édias ${ }^{1}$ de potencial hídrico foliar $\left(\Psi_{\mathrm{f}}\right)$, condutância estomática $\left(\mathrm{g}_{\mathrm{s}}\right)$, temperatura foliar (Tf) e de produtividade de grãos (PG) de 20 genótipos de feijão-caupi, sob dois regimes hídricos

\begin{tabular}{|c|c|c|c|c|c|c|c|c|}
\hline \multirow[t]{2}{*}{ Genótipos } & \multicolumn{2}{|c|}{$\begin{array}{c}\Psi_{\mathrm{f}} \\
(\mathrm{MPa})\end{array}$} & \multicolumn{2}{|c|}{$\begin{array}{c}g_{s} \\
\left(\mathrm{~mol} \mathrm{~m}^{2} \mathrm{~s}^{-1}\right)\end{array}$} & \multicolumn{2}{|c|}{$\begin{array}{c}\text { Tf } \\
(\stackrel{\circ}{ })\end{array}$} & \multicolumn{2}{|c|}{$\begin{array}{c}\text { PG } \\
\left(\mathrm{kg} \mathrm{ha}^{-1}\right)\end{array}$} \\
\hline & *SE & $* * \mathbf{C E}$ & SE & CE & SE & CE & SE & CE \\
\hline BRS Paraguaçu & $-0,85 c$ & $-1,22 \mathrm{~g}$ & $0,27 a$ & $0,11 \mathrm{a}$ & $28,2 b$ & $29,7 \mathrm{C}$ & 1529 a & $712 \mathrm{a}$ \\
\hline Pingo-de-ouro-1-2 & $-0,93 c$ & $-1,51$ e & $0,26 a$ & $0,09 \mathrm{~b}$ & 30,4 a & $33,1 \mathrm{a}$ & $1500 \mathrm{a}$ & $667 a$ \\
\hline Pingo-de-ouro-2 & $-1,12$ a & $-1,88 \mathrm{~b}$ & $0,20 d$ & $0,06 \mathrm{c}$ & 30,0 a & $34,2 \mathrm{a}$ & $1236 a$ & $642 \mathrm{a}$ \\
\hline Canapuzinho,PE & $-1,08 a$ & $-1,71 d$ & $0,19 d$ & $0,05 \mathrm{c}$ & $30,5 \mathrm{a}$ & $34,0 \mathrm{a}$ & 1230 a & $584 a$ \\
\hline TE-898 & $-1,08$ a & $-1,94 b$ & $0,20 d$ & $0,04 \mathrm{~d}$ & $29,1 \mathrm{~b}$ & 33,4 a & 1023 b & $562 a$ \\
\hline BRS Xiquexique & $-0,88 c$ & $-1,62 \mathrm{e}$ & $0,24 b$ & $0,07 \mathrm{c}$ & $29,6 \mathrm{~b}$ & $34,3 \mathrm{a}$ & $1245 a$ & $538 a$ \\
\hline Canapuzinho-2 & $-1,02$ b & $-1,54$ e & $0,23 b$ & $0,06 \mathrm{c}$ & $31,0 \mathrm{a}$ & $34,1 \mathrm{a}$ & 1380 a & $533 a$ \\
\hline CNCx 689-128G & $-0,97 c$ & $-1,39 f$ & $0,24 b$ & $0,06 \mathrm{c}$ & $29,5 b$ & $32,6 a$ & 1408 a & $520 a$ \\
\hline IPA-206 & $-0,94 c$ & $-1,55$ e & $0,22 \mathrm{c}$ & $0,06 \mathrm{c}$ & $29,3 b$ & $33,9 a$ & 1194 a & $504 a$ \\
\hline Tvu 36 & $-1,02 b$ & $-1,77 \mathrm{C}$ & $0,19 d$ & $0,07 \mathrm{c}$ & $29,7 \mathrm{~b}$ & $33,2 \mathrm{a}$ & 1074 b & $494 \mathrm{a}$ \\
\hline Patativa & $-1,03 b$ & $-1,69 d$ & $0,22 \mathrm{c}$ & $0,07 \mathrm{C}$ & $30,3 \mathrm{a}$ & 33,1 a & $1107 b$ & $480 \mathrm{a}$ \\
\hline Canapu,BA & $-0,93 c$ & $-1,41 \mathrm{f}$ & $0,20 d$ & $0,07 \mathrm{C}$ & 30,2 a & $31,5 \mathrm{~b}$ & 1073 b & $463 a$ \\
\hline Canapuzinho & $-1,02 b$ & $-1,83 \mathrm{c}$ & $0,22 \mathrm{c}$ & $0,06 \mathrm{c}$ & $29,7 \mathrm{~b}$ & $34,1 \mathrm{a}$ & 1248 a & $456 a$ \\
\hline Pitiuba & $-1,00 \mathrm{~b}$ & $-1,56 \mathrm{e}$ & $0,20 d$ & $0,06 \mathrm{c}$ & $29,0 \mathrm{~b}$ & $33,1 \mathrm{a}$ & $1078 b$ & $386 b$ \\
\hline Pingo-de-ouro-1 & $-0,99 b$ & $-1,58 \mathrm{e}$ & $0,26 a$ & $0,05 \mathrm{c}$ & 30,2 a & $33,2 \mathrm{a}$ & 1276 a & $359 b$ \\
\hline BR17- Gurguéia & $-1,06$ a & $-1,59$ e & $0,21 \mathrm{c}$ & $0,07 \mathrm{c}$ & 30,4 a & $33,9 a$ & 1157 b & $342 b$ \\
\hline Capela & $-0,96 c$ & $-1,52 \mathrm{e}$ & $0,16 \mathrm{e}$ & $0,06 \mathrm{~d}$ & 31,5 a & $33,8 \mathrm{a}$ & $613 c$ & $338 b$ \\
\hline Epace-10 & $1,05 \mathrm{~b}$ & $-1,70 d$ & $0,19 d$ & $0,04 d$ & $30,0 a$ & $33,5 \mathrm{a}$ & $1013 b$ & $320 \mathrm{~b}$ \\
\hline Santo Inácio & $-1,14$ a & $-1,94$ a & $0,16 \mathrm{e}$ & $0,03 \mathrm{~d}$ & 30,7 a & $34,5 a$ & $947 b$ & $246 b$ \\
\hline Tracuateua-192 & $-1,04 b$ & $-2,05 a$ & $0,22 \mathrm{c}$ & $0,04 \mathrm{~d}$ & $29,1 \mathrm{~b}$ & 34,5 a & $1024 \mathrm{~b}$ & $171 b$ \\
\hline Média & $-1,00$ & $-1,65$ & 0,21 & 0,06 & 29,9 & 33,4 & 1167 & 466 \\
\hline C.V. (\%) & 6,23 & 4,41 & 7,12 & 14,35 & 3,08 & 3,20 & 18,60 & 39,71 \\
\hline
\end{tabular}

${ }^{1}$ Médias seguidas da mesma letra na coluna, não diferem entre si pelo teste de Scott-Knott a $5 \%$ de probabilidade

* SE - Sem Estresse, ** CE - Com Estresse 
Nenhum dos tratamentos sob deficiência hídrica alcançou valores de $\varnothing_{\mathrm{f}}$ inferiores a -2,5 MPa que, segundo Boyer (1978), é considerado um limite letal para o feijão-caupi. Plantas com potenciais hídricos foliares entre -1,0 e -2,0 MPa indicam uma deficiência hídrica moderada e relativa tolerância à seca, afirmam Taiz \& Zeiger (2004). O genótipo Tracuateua-192 apresentou a maior redução do $\Psi_{\mathrm{f}}(-2,05 \mathrm{MPa})$. Esse estresse hídrico foi mais severo do que os obtidos por Mendes et al. (2007) que registraram valor médio de -1,05 MPa para o genótipode feijãode-corda Epace 10 no estádio vegetativo. O maior nível de estresse hídrico obtido neste estudo pode ser atribuído ao fato do mesmo ter sido imposto na fase reprodutiva, considerada a fase mais sensível ao déficit hídrico. Gomes Filho \& Tahin (2002) corroboram com esta hipótese, pois relataram que o período crítico da cultura, provocado pelo estresse hídrico, se restringe a uma fase relativamente curta entre a época de floração e o início do enchimento dos grãos (Bezerra et al., 2003).

Ainda sob estresse hídrico verificou-se elevada redução dos valores de potencial hídrico foliar em alguns genótipos, ou seja, $\varnothing_{\mathrm{f}}$ abaixo da média (-1,65 MPa) em alguns genótipos durante a ocorrência da deficiência de água no solo resultado devido, possivelmente, ao fechamento dos estômatos acarretando, com isto, diminuição na atividade fotossintética. Boyer (1978) constatou que a taxa de fotossíntese líquida da soja não foi afetada até o $\varnothing_{\mathrm{f}}$ de $-1,1 \mathrm{MPa}$, reduzindo sua eficiência a $60 \%$, com o $\emptyset_{f}-1,6 \mathrm{Mpa}$. Entretanto, na cultura do milho o autor verificou reduções a partir-0,35 MPa e, ao atingir $-1,6 \mathrm{MPa}$, sua eficiência fotossintética foi de apenas $25 \%$ e acrescenta, ainda, que esta variabilidade pode ser devida à capacidade da planta de manter os estômatos abertos em $\emptyset_{\mathrm{f}}$ mais baixo, permitindo que a fotossíntese se processe por um período mais longo, nas espécies mais resistentes à seca.

Os genótipos BRS Paraguaçu, Pingo-de-ouro-1-2, Canapu,BA e CNCx 689-128G, sob deficiência hídrica, mantiveram um $\varnothing_{\mathrm{f}}$ maior que os demais genótipos (Tabela 3 ), evidenciando um controle maior na abertura estomática, que é uma característica de tolerância à seca em feijão-caupi (Subbarao et al., 1995). Já os genótipos Tracuateu-192 e Santo Inácio, por apresentarem maior redução no $\emptyset_{\mathrm{f}, \text { ocasionando }}$ perda de turgescência e maior fechamento dos estômatos tiveram, provavelmente como consequência, maior redução na produção de fotossintatos, resultando no menor rendimento de grãos, característica que revela a sensibilidade desses genótipos ao déficit hídrico; apesar disto, os genótipos Pingode-ouro-2 e TE-898 alcançaram altos rendimentos, mesmo sofrendo forte redução do $\emptyset_{\mathrm{f}}$ e da $\mathrm{g}_{\mathrm{s}}$ fato este explicado por Turner (1997), que os classifica como tolerantes à seca, com alto potencial hídrico e acrescenta que a tolerância da planta ao déficit hídrico parece ser um importante mecanismo de resistência para manter o processo produtivo em condições de baixa disponibilidade de água às plantas.

Sob condições de irrigação plena a condutância estomática $\left(\mathrm{g}_{\mathrm{s}}\right)$ variou de $0,16 \mathrm{~mol} \mathrm{~m}^{2} \mathrm{~s}^{-1}$ para os genótipos Santo Inácio e Epace-10 a 0,27 mol m² $\mathrm{s}^{-1}$ para o tratamento BRS Paraguaçu (Tabela 3). De forma geral, verificou-se que nas plantas mantidas sob irrigação plena ag apresentou uma variação de $68 \%$. Esta elevada variação pode ser explicada, sobremaneira, por pequenas respostas dessa variável a fatores do ambiente, como a temperatura e a umidade do ar. Mansfield et al. (1990) relatam que outros fatores não hidráulicos, são capazes de regular o comportamento estomático e que as células-guarda apresentam grande sensibilidade aos fatores físicos e químicos do meio; verificou-se, também, que nove genótipos ficaram acima da média geral $\left(0,21 \mathrm{~mol} \mathrm{~m}^{2} \mathrm{~s}^{-1}\right)$.

Observou-se, entre os tratamentos sob déficit, uma variação na $\mathrm{g}_{\mathrm{s}}$ de $0,03 \mathrm{~mol} \mathrm{~m}^{2} \mathrm{~s}^{-1}$ para o tratamento Santo Inácio a 0,11

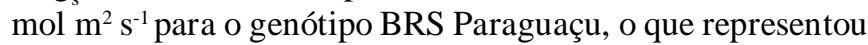
uma variação de $267 \%$. Resultados que se assemelham aos de Oliveira et al. (2005), que estudaram a condutância estomática como indicador de estresse hídrico em feijão-caupi encontrando valores de $\mathrm{g}_{\mathrm{s}}$ variando de 0,03 a $0,18 \mathrm{~mol} \mathrm{~m}^{2} \mathrm{~s}^{-1}$, confirmado também em estudo de Mendes et al. (2007) em cultivares de feijão-caupi, com valores de $g_{s}$ de 0,035,0,04 e 0,02 $\mathrm{mol} \mathrm{m}^{2} \mathrm{~s}^{-1}$, respectivamente, porém Endres et al.(2010) verificaram, em feijoeiro comum, uma $\mathrm{g}_{\mathrm{s}}$ de $0,01 \mathrm{~mol} \mathrm{~m}^{2} \mathrm{~s}^{-1}$, chegando quase ao total fechamento dos estômatos, resultado de um estresse hídrico severo.

Os genótipos BRS Paraguaçu e Pingo-de-ouro-1-2 apresentaram maior valor de $\mathrm{g}_{\mathrm{s}}$ em relação aos outros genótipos, sob condições de deficiência hídrica (Tabela 3) demonstrando eficiência no controle estomático, passível de permitir uma alta atividade fotossintética, o que é desejável para genótipos mais tolerantes à seca, segundo Kramer \& Boyer (1995). O fechamento dos estômatos, juntamente com a inibição do aumento da área foliar, está entre as primeiras respostas à seca, protegendo as plantas contra as perdas de água, a qual pode resultar em desidratação celular, fechamento da cavidade xilemática e até morte neste sentido; plantas que conseguem rapidamente evitar a perda de água por meio do fluxo estomático e manter, pelo menos temporariamente, taxas fotossintéticas razoáveis, apresentam bom comportamento fisiológico em situações de deficiência hídrica. Dos genótipos estudados o que mais se aproxima desse padrão é o TE-898 que, mesmo tendo reduzido significativamente o fluxo estomático, conseguiu manter taxas fotossintéticas similares às do grupo dos genótipos com alta produtividade, o que também comprovaram Turk \& Hall (1990), ao relatarem que o feijãocaupi cultivado em condições de campo apresentou o fechamento estomático como principal estratégia de fuga à seca e manteve, assim, um status hídrico razoável.

A imposição do déficit hídrico conferiu alta redução na $g_{s}$ fato explicado em decorrência do decréscimo na disponibilidade de água no solo, que ocasiona queda no potencial de água nas folhas resultando no fechamento dos estômatos, o que eleva a perda de turgescência. Constatou-se, por outro lado, nas plantas submetidas ao déficit hídrico do solo, que $\mathrm{a} \mathrm{s}_{\mathrm{s}}$ se correlacionou positivamente com o $\emptyset_{f}$ desta forma, quanto menor o valor do $\varnothing_{f}$ menor a $g_{s}$. Paiva et al. (2005) encontraram redução da condutância estomática em feijão-comum em resposta a baixos valores de potencial hídrico do solo e a altos valores de déficit de pressão de vapor e aumento da condutância estomática sob altos valores de potencial hídrico do solo além de baixos valores de déficit de pressão de vapor. Os resultados em relação a esta variável estão de acordo com os obtidos por Gholz et al. (1990), de que o feijãocaupi fecha seus estômatos aos primeiros sinais de deficiência 
hídrica. Então, as plantas tentam reduzir a transpiração e conservar valores elevados de $\varnothing_{\mathrm{f} ;} \operatorname{logo}$, um dos principais mecanismos de adaptação da cultura ao déficit hídrico é evitar a desidratação dos tecidos, embora isto resulte na diminuição de sua capacidade produtiva, sobretudo quando o estresse é prolongado. Para Laffay \& Louguet (1990), o feijão-caupi apresenta, simultaneamente, um rápido fechamento e alta tolerância protoplasmática, estratégias adaptativas que não são opostas, permitindo aos melhoristas vegetais levar em conta essas duas características em estudos de tolerância à seca.

Sob déficit hídrico os genótipos Epace-10, Tracuateua-192, Santo Inácio e Capela apresentaram baixos valores de condutância estomática (Tabela 3), em resposta aos baixos potenciais de água na folha, revelando-os como sensíveis à deficiência hídrica, visto que baixa condutância resulta em fechamento dos estômatos tendo, como consequência, menor taxa fotossintética, resultando em menores rendimentos de grãos (Taiz \& Zeiger, 2004).

Com relação à temperatura média foliar (Tf), notou-se uma elevação média de $3,5^{\circ} \mathrm{C}$ quando os genótipos foram submetidos a déficit hídrico (Tabela 3). Resultado semelhante foi obtido por Oliveira et al. (2005), ao constatarem que os diferenciais médios de temperatura da folha em relação à do ar, foram crescentes à medida em que progredia a deficiência hídrica, chegando a uma diferença de $3,2{ }^{\circ} \mathrm{C}$. Endres et al. (2010) constataram, em pesquisa com feijão comum, aumentos diferenciais na temperatura foliar e na relação temperatura foliar/ ambiente, alcançando $2,2^{\circ} \mathrm{C}$ com o déficit hídrico aplicado aos 44 DAS. Sob irrigação plena os genótipos apresentaram valores de Tf bem próximos, sinalizando que as plantas estavam sob as mesmas condições hídricas. O genótipo BRS Paraguaçu mostrou Tf abaixo da temperatura ambiente enquanto os outros genótipos apresentaram ligeiro aumento. Conforme Angelocci (2002), a temperatura da folha tende a acompanhar a do ambiente. Oliveira et al. (2005) também acrescentam que a manutenção da temperatura igual ou ligeiramente inferior à do ambiente, comprova a capacidade de refrigeração das plantas, via transpiração por meio da manutenção de elevada condutância estomática, com o intuito de manter a planta protegida das faixas térmicas muito elevadas.

Quando se contrastaram os genótipos da condição de irrigação plena com os da condição de supressão hídrica, conferiu-se uma leve elevação na Tf nos genótipos Canapu, BA e BRS Paraguaçu, com 4 e 5\%, respectivamente, enquanto os genótipos BRS Xiquexique (Freire Filho et al., 2008), Canapuzinho e Tracuateua-192, apresentaram 15, 15 e 19\%, respectivamente, consideradas as maiores elevações na Tf (Tabela 3). A diferença de temperatura foliar em plantas com e sem estresse se fundamenta no estado hídrico das plantas, no comportamento estomático e na perda de calor latente por meio da transpiração. Apesar disso, todo este processo muda para cada espécie, conforme a intensidade e a duração do estresse hídrico (Nogueira et al., 2001). Em feijão comum Oliveira et al. (2005) e Endres et al. (2010) reportaram que a elevação da temperatura foliar em resposta ao estresse hídrico pode ser explicada pela redução na perda de calor latente através da transpiração que, normalmente, reduz nessas condições.
Os resultados da relação da temperatura foliar com a do ambiente (Tf/Ta) estão apresentados na Figura 1. Sob irrigação plena a relação Tf/Ta média foi de 1,03, enquanto na condição de estresse hídrico este valor foi de 1,15 . Referidos resultados indicam uma elevação média de $3 \%$ na relação Tf/Ta na condição de suprimento hídrico adequado e de $15 \%$ quando da imposição do estresse hídrico.

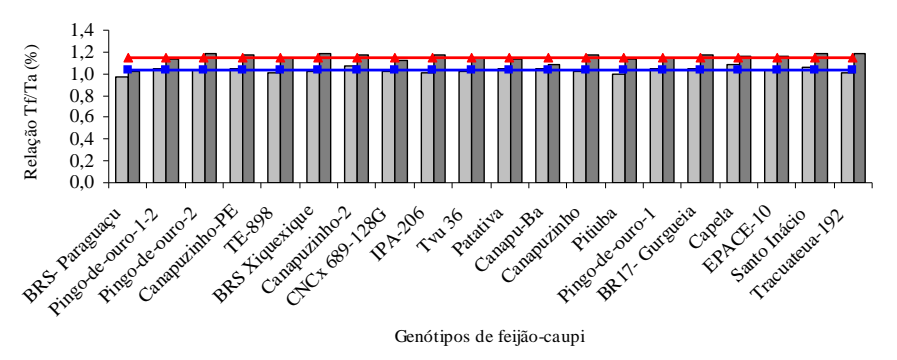

Figura 1. Relação entre Temperatura foliar e Temperatura ambiente de 20 genótipos de feijão-caupi, nos experimentos sem e com estresse hídrico, no perío do de agosto a outubro de 2008

O genótipo BRS Paraguaçu indicou valores de Tf/Ta inferiores aos dos demais genótipos, nas duas condições estudadas, enquanto sob déficit hídrico os genótipos que apresentaram as maiores elevações na relação $\mathrm{Tf} / \mathrm{Ta}$, foram Canapuzinho com 13\%, TE898 com 13\%, IPA-206 com 14\% e Tracuateua-192 com 16\%. Valores semelhantes obtiveram Oliveira et al. (2005) em feijão-comum, que encontraram uma elevação média de $15 \%$ na relação $\mathrm{Tf} / \mathrm{Ta}$, com leituras realizadas às $8 \mathrm{~h}$ da manhã. No entanto, quando as leituras foram realizadas ao meio-dia solar a relação Tf/Ta subiu para $60 \%$, resultados que indicam o elevado efeito da Ta sobre as plantas que, nos horários de maior Ta, resultaram em maiores efeitos deletérios do déficit hídrico sobre os vegetais, ou seja, o aumento da temperatura do ar e da folha tende a aumentar a diferença de concentração de vapor folha-ar. Uma vez mantidos constantes, as condutâncias difusivas na via de fluxo, o aumento da temperatura do ar tende a provocar acréscimo da transpiração, até o ponto em que a regulação estomática passa a atuar no sentido de não permitir uma perda excessiva de água.

Oliveira et al. (2005) acrescentam, ainda, que a temperatura da folha apresenta estreita relação com a resistência estomática pois, com o aumento da resistência estomática, tem-se diminuição da transpiração foliar e incremento na temperatura das folhas. Segundo Milburn (1979), a transpiração exerce efeitos importantes na agricultura tropical, como o resfriamento da folha visto que, para evaporar na folha, a água retira sua energia térmica, reduzindo a temperatura foliar de $2 \mathrm{a} 3{ }^{\circ} \mathrm{C}$. Endres et al. (2010) sugerem que a relação entre temperatura foliar e ambiente pode ser usada como indicador das condições hídricas da planta o qual, devidamente obtido, pode ser utilizado para indicar o estresse térmico.

O rendimento médio de grãos sofreu forte influência da supressão hídrica em todos os genótipos estudados (Tabela 3). A produtividade de grãos (PG) média dos genótipos sob irrigação plena alcançou $1.167 \mathrm{~kg} \mathrm{ha}^{-1}$, enquanto no experimento sob deficiência hídrica a PG foi de $466 \mathrm{~kg} \mathrm{ha}^{-1}$, resultando em 
uma redução de $60 \%$ na $\mathrm{PG}$, quando se comparam as duas condições. Esses resultados foram maiores que os obtidos por Bezerra et al. (2003), que observaram redução na produtividade de grãos de 40, 29 e 20,7\%, respectivamente, quando o déficit hídrico foi imposto aos estádios de florescimento e enchimento de vagens. O fato do déficit hídrico imposto aos estádios acima citados não resultar em grandes perdas de produção foi devido, segundo Bezerra et al. (2003), aos intervalos dos estádios fenológicos da cultura, que foram bastante curtos (floração: 10 dias e enchimento de grãos, 9 dias). Embora esteja de acordo com Carvalho et al. (2000) que, estudando o efeito do déficit hídrico sobre o rendimento do feijão-caupi, encontraram redução no rendimento de grãos variando de 34 a 81\%, para reposição da água consumida pela planta de 80 e $20 \%$, respectivamente, com déficit hídrico imposto à fase de floração. Sousa et al. (2009) verificaram, quando estudaram o estresse hídrico afetando os componentes de rendimento do feijoeiro, reduções de $68,61 \%$ na produtividade de grãos para o déficit hídrico aplicado em plena floração, resultado este que corrobora com o presente estudo.

Para o regime de irrigação plena os genótipos apresentaram variação de $150 \%$ entre a menor e a maior produtividade, cujo resultado revela que, mesmo sob condições de suprimento adequado de água durante todo o ciclo da cultura, é possível selecionar genótipos mais produtivos. Os genótipos BRS Paraguaçu, Pingo-de-ouro-1-2, Canapu, BAe CNCx 689$128 \mathrm{Gsob}$ deficiência hídrica, mantiveram um $\emptyset_{\mathrm{f}}$ maior que os demais genótipos, evidenciando maior controle na abertura estomática, que resultou em maiores produtividades de grãos. Este fato corrobora com a afirmação de que uma cultivar mais tolerante à seca apresenta eficientes mecanismos que lhe conferem tolerância à seca (Santos et al., 2010).

Os valores de produtividade de grãos sob estresse hídrico apresentaram variação de 171 a $712 \mathrm{~kg} \mathrm{ha}^{-1}$ para os genótipos Tracuateua-192 e BRS Paraguaçu, respectivamente, cujo resultado conferiu um aumento de produtividade de $316 \%$ para o genótipo BRS Paraguaçu e foi semelhante aos de Bezerra et al. (2003), que verificaram uma PG máxima de 745,50 $\mathrm{kg} \mathrm{ha}^{-1}$ para o feijão-caupi com déficit hídrico na fase de floração. A PG do genótipo BRS Paraguaçu em relação à produtividade média do experimento foi $52 \%$ maior, sendo este aumento de produtividade resultado das respostas fisiológicas relacionadas à eficiência no uso da água (Taiz \& Zeiger, 2004), revelando uma tolerância maior aos efeitos do déficit hídrico por parte deste genótipo. Os genótipos Santo Inácio e Tracuateua-192 revelaram intolerância à seca, demonstrada através de suas respostas fisiológicas, além de forte redução no rendimento de grãos, sofrida pela imposição do déficit hídrico na fase reprodutiva, provavelmente em resposta à menor produção de fotoassimilados (Kramer \& Boyer, 1995). Os resultados de Carvalho et al. (2000) indicam que o rendimento de grãos sofreu queda acentuada, sempre que se acentuou o déficit hídrico, independente da etapa fenológica em que este ocorreu. Endres et al. (2010) também constataram que o déficit hídrico causa redução no rendimento de grãos, independentemente do estádio fenológico em que este é aplicado; entretanto, os mesmos ressaltam que o estresse ocorrido na fase reprodutiva tem efeitos mais desastrosos para a planta.
Os genótipos que apresentaram as menores produtividades de grãos foram aqueles que evidenciaram maior sensibilidade ao déficit hídrico, comprovado pelas condições fisiológicas apresentadas, tais como: forte redução no potencial hídrico foliar, concorrendo para um elevado fechamento estomático, resultando em menor produção de fotoassimilados para enchimento das vagens, exatamente pelo impedimento da entrada de $\mathrm{CO}_{2}$ (Bergamaschi et al., 2004; Endres et al., 2010), além da forte elevação da temperatura foliar que, no caso do genótipo Tracuateua-192, chegou a $5,4^{\circ} \mathrm{C}$. A avaliação do status hídrico das plantas quando submetidas à deficiência hídrica nas fases vegetativa e reprodutiva, demonstra que cultivares de feijão-caupi sofrem reduções significativas no $\emptyset_{f}, g_{s} e$ transpiração foliar, com consequente aumento na temperatura da folha (Mendes et al., 2007).

\section{CONCLusões}

1. O estresse hídrico determinou aumento tanto na temperatura da folha como na relação temperatura foliar/ambiente e reduziu o potencial hídrico foliar, condutância estomática e a produtividade de grãos.

2. Os genótipos BRS Paraguaçu, Pingo-de-ouro-1-2, Canapu, BAe CNCx 689-128G e TE898, apresentaram tolerância ao déficit hídrico.

3. Os genótipos Santo Inácio e Tracuateu-192 são intolerantes ao déficit hídrico moderado.

\section{LITERATURA CITADA}

Angelocci, L. R. Água na planta e trocas gasosas/energéticas com a atmosfera: introdução ao tratamento biofísico. ed. Piracicaba, SP, 2002, v.1, 272p.

Bastos, E. A.; Andrade Júnior, A. S. Boletim agrometeorológico do ano de 2008 para o município de Teresina, PI. Teresina: Embrapa Meio-Norte, 2008, 37p. Documentos, 181

Bastos, E. A.; Ferreira, V. M.; Silva, C. R.; Andrade Júnior, A. S. Evapotranspiração e coeficiente de cultivo do feijão-caupi no vale do Gurguéia, PI. Irriga, v.13, p.182-190, 2008.

Bergamaschi, H.; Dalmago, G. A.; Bergonci, J. I.; Bianchi, C. A. M.; Müller, A. G.; Comiran, F.; Heckler, B. M. M. Distribuição hídrica no período crítico do milho e produção de grãos. Pesquisa Agropecuária Brasileira, v.39, p.831-839, 2004.

Bezerra, F. M. L.; Araripe, M. A. E.; Teófilo, E. M.; Cordeiro, L. G.; Santos, J. J. A. Feijão-caupi e déficit hídrico em suas fases fenológicas. Ciência Agronômica, v.34, p.5-10, 2003.

Boyer, J. S. Water deficits and photosynthesis. In: Kozlowski, T.T. (ed.) Water deficits and plant growth. New York: Academic Press, v.4, p.154-191, 1978.

Carvalho, J. A.; Pereira, G. M.; Andrade, M. J. B.; Roque, M. W. Efeito do déficit hídrico sobre o rendimento do feijão-caupi [Vigna unguiculata (L.) Walp.]. Ciência Agrotécnica, v.24, p.710-717, 2000. 
CONAB - Companhia Brasileira de Abastecimento. Oitavo levantamento de avaliação da safra 2007/2008. Brasília, CONAB, 2008. 22p. <http://www.conab.gov.br/conabweb/ download/safra8_levamtamento_mai2008.pdf>. 30 Out. 2008.

Endres, L.; Souza, J. L.; Teodoro, L.; Marroquim, P. M. G.; Santos, C. M.; Brito, J. E. D. Gas exchange alteration caused by water deficit during the bean reproductive stage. Revista Brasileira de Engenharia Agrícola e Ambiental, v.14, p.1116, 2010.

Freire Filho, F. R.; Rocha, M. M.; Queiroz, V. R.; Sittolin, I. M.; Carvalho, H. W. L. BRS Xiquexique: Cultivar de feijão-caupi rica em ferro e zinco. Teresina: Embrapa Meio-Norte, 2008, 4p. Comunicado Técnico

Gomes Filho, R. R.; Tahin, J. F. Respostas fisiológicas de cultivares de caupi (Vigna unguiculata) eretos e decumbentes a diferentes níveis de irrigação. Engenharia na Agricultura, v.10, p.56-60, 2002.

Gholz, H. L.; Ewel, K. C.; Teskey, R. O. Water and forest productivity. Forest Ecological Management, v.30, p.1-18, 1990.

Guimarães, C. M.; Stone, L. F.; Brunini, O. Adaptação do feijoeiro comum (Phaseolus vulgaris L.) à seca. Revista Brasileira de Engenharia Agrícola eAmbiental, v.10, p.70-75, 2006.

Kramer, P. J.; Boyer, J. S. Water relations of plants and soils. Academic Press, New York: 1995.495p.

Laffay, D.; Louguet, P. Stomatal responses and drought resistance. Bulletin de la Societ Botanique de France: Actaualites Botaniques, v.137, p.47-60, 1990.

Larcher, W. Ecofisiologia vegetal. São Carlos: ed. Rima Artes e Textos, 2000. 531p.

Lima, J. R. S.; Antonino, A. C. D.; Soares, W. A.; Silva, I. F. Estmativa da evapotranspiração do feijão-caupi utilizando o modelo de Penman-Monteith, v.11, p.477-491, 2006.

Mansfield, T. A.; Hetherington, A. M.; Atkinson, C. J. Some current aspects of stomatal physiology. Annual Review of Plant Physiology and Plant Molecular Biology, v.41, p.5575, 1990.

Mendes, R. M. S.; Távora, F. J. A. F.; Pinho, J. L. N.; Pitombeira, J. B. Relações fonte-dreno em feijão-de-corda submetido à deficiência hídrica. Ciência Agronômica, v.38, p.95-103, 2007.

Micheletto, S.; Rodriguez-Uribe, L.; Hernandez, R.; Richins, R.D.; Cury, J.; O'Connell, M. A. Comparative transcript profiting in roots of Phaseolus acutifolus and P. vulgaris under water deficit stress. Plant Science, v.173, p.510-520, 2007.

Milburn, J. Water flow in plants. London: Longman, p.225. 1979.

Nascimento, J. T.; Pedrosa, M. B.; Tavares Sobrinho, J. Efeito da variação dos níveis de água disponível no solo sobre crescimento e produção de feijão-caupi, vagens e grãos verdes.Horticultura Brasileira, v.22, p.174-177, 2004.

Nepomuceno, A. L.; Neumaier, N.; Farias, J. R. B.; Oya, T. Tolerância à seca em plantas: Mecanismos fisiológicos e moleculares. Revista Biotecnologia, Ciência \& Desenvolvimento, p.12-18, 2001.
Nogueira, R. J. M. C.; Moraes, J. A. P. V; Burity, H. A.; Bezerra Neto, E. Alterações na resistência à difusão de vapor das folhas e relações hídricas em aceroleiras submetidas a déficit de água. Revista Brasileira de Fisiologia Vegetal, v.13, p.75-87, 2001.

Nogueira, R. J. M. C.; Santos, R. C.; Bezerra Neto, E; Santos, V. F. dos. Comportamento fisiológico de dois cultivares de amendoim submetidos a diferentes regimes hídricos. Pesquisa Agropecuária Brasileira, v.33, p.1963-1969, 1998.

Oliveira, A. D.; Fernandes, E. J.; Rodrigues, T. J. D. Condutância estomática como indicador de estresse hídrico em Feijão. Engenharia Agrícola, v.25, p.86-95, 2005.

Paiva, A. S.; Fernandes, E. J.; Rodrigues, T. J. D.; Turco, J. E. P. Condutância estomática em folhas de feijoeiro submetido a diferentes regimes de irrigação. Engenharia Agrícola, v.25, p.161-169, 2005.

Ribeiro, R. V.; Santos, M. G.; Souza, G. M.; Machado, E. C.; Oliveira R. F.; Angelocci, L. R.; Pimentel, C. Environmental effects on photosynthetic capacity of bean genotypes.Pesquisa Agropecuária Brasileira, v.39, p.615623, 2004.

SAEG - Sistema para Análises Estatísticas. SAEG, Versão 9.1., Fundação Arthur Bernardes - UFV - Viçosa, 2007.

Santos, F. S.; Lima, G. P. P.; Morgado, L. B. Tolerância e caracterização bioquímica em feijão-caupi submetido a estresse hídrico na pré-floração.Naturalia, v.33, p.34-44, 2010.

Scholander, P. F.; Hammel, H. T.; Hemmingsen, E. A.; Bradstreet, E. D. Sap pressure in vascular plants. Science, v.148, p.339346, 1965.

Sousa, M. A.; Lima, M. D. B.; Silva, M. V. V.; Andrade, J. W. S. Estresse hídrico e profundidade de incorporação do adubo afetando os componentes de rendimento do feijoeiro. Pesquisa Agropecuária Tropical,v.39, p.175-182, 2009.

Souza, R. P.; Machado, E. C.; Silva, J. A. B.; Lagoa, A. M. M. A.; Silveira, J. A. G. Photoshynthetic gás Exchange, chorophyll fluorescence and some associated metabolic changes in cowpea (Vigna unguiculata) during water stress and recovery. Enviromental and Experimental Botany, v.51, p.45-56, 2004.

Subbarao, G. V.; Johansen, C.; Slinkard, A. E.; Rao, R. C. N.; Saxena, N. P.; Chauha, Y. S. Strategies for improving drought resistance in grain legumes. Critical Reviews in Plant Science, v.14, p.469-529, 1995.

Taiz, L.; Zeiger, E. Fisiologia vegetal. 3. ed. Porto Alegre: Artmed, 2004. 719p.

Távora, F. J. A. F.; Melo O. I. F. Resposta de cultivares de amendoim a ciclos de deficiência hídrica: crescimento vegetativo, reprodutivo e relações hídricas. Ciência Agronômica, v.22, p.47-60, 1991.

Turk, K. J.; Hall, A. E. Drought adaptation of cowpea. II Influence of drought on plant water and relations with seed yield. Agronomy Journal, v.72, p.421-27, 1990.

Turner, N. C. Further progress in crop water relations. In: Advances in agronomy (D.L. Sparks, ed.). New York: Academic Press, 1997. p.293-337. 